\title{
Differing effects of two synthetic phonics programmes on early reading development
}

Laura R. Shapiro ${ }^{1} *$ and Jonathan Solity ${ }^{2}$

${ }^{1}$ School of Life and Health Sciences, University of Aston, Birmingham B4 7ET, UK

${ }^{2}$ Optima, P.O. Box 4562, Leamington Spa CV31 9EW, UK and University College London, London WC1E 6BT, UK

*Requests for reprints should be addressed to Dr. Laura R. Shapiro, School of Life and Health Sciences, University of Aston, Birmingham B4 7ET, UK (e-mail:

1.r.shapiro@aston.ac.uk).

\section{Acknowledgments}

This study was supported by the Learning Skills Research http://www.learningskillsresearch.com. We are immensely grateful to the staff and pupils from Birmingham schools for their support and participation and to the Research Assistants from Aston University who collected the data.

\section{Disclosure of interests}

The framework for teaching reading within the Early Reading Research (ERR) programme was developed by Jonathan Solity, who is now the director of Optima (a psychological and educational research based consultancy) and an Honorary Research Fellow at University College London. Optima offers a consultancy service to local authorities and schools on teaching reading, writing, language and maths. Advice and training on teaching reading draws on a wide range of research that includes elements of the original ERR framework for teaching reading.

\section{Author roles}

Research design (Shapiro \& Solity), data collection and analysis (Shapiro), manuscript drafting and final approval (Shapiro \& Solity). 


\begin{abstract}

\section{Background}

Synthetic phonics is the widely accepted approach for teaching reading in English: children are taught to sound out the letters in a word then blend these sounds together.
\end{abstract}

\title{
Aims
}

We compared the impact of two synthetic phonics programmes on early reading.

\section{Sample}

Children received Letters and Sounds (L\&S; 7 schools) which teaches multiple lettersound mappings or Early Reading Research (ERR; 10 schools) which teaches only the most consistent mappings plus frequent words by sight.

\section{Method}

We measured phonological awareness (PA) and reading from school entry to the end of the second (all schools) or third school year (4 ERR, 3 L\&S schools).

\section{Results}

PA was significantly related to all reading measures for the whole sample. However, there was a closer relationship between PA and exception word reading for children receiving the $L \& S$ programme. The programmes were equally effective overall, but their impact on reading significantly interacted with school-entry PA: children with poor PA at school entry achieved higher reading attainments under ERR (significant group difference on exception word reading at the end of the first year), whereas children with good PA performed equally well under either programme.

\section{Conclusions}

The more intensive phonics programme (L\&S) heightened the association between PA and exception word reading. Although the programmes were equally effective for most children, results indicate potential benefits of ERR for children with poor PA. We suggest that phonics programmes could be simplified to teach only the most consistent mappings plus frequent words by sight. 
Differing Effects of Two Synthetic Phonics Programmes on Early Reading Development

There is a strong consensus that early literacy teaching in English should focus on teaching letter-sound relationships in an explicit, organised and sequenced fashion (systematic phonics; Ehri, Nunes, Stahl \& Willows, 2001; Torgerson, Brooks \& Hall, 2006). The National Curriculum in England (DfE, 2013) makes more specific recommendations and advocates that children should be taught to sound out each phoneme in a word then blend these phonemes together to pronounce the whole word (synthetic phonics). A synthetic phonics approach is strongly aligned with theories of early reading development. For the beginning reader, each written word will be initially unfamiliar, until the letters are translated into speech sounds (decoded). Ehri (e.g., 2008) describes early decoding as a highly effortful process in which each grapheme must be translated one by one (e.g., "b-l-e-n-d, blend"; phonic decoding). Each time a child successfully decodes a word, they have the opportunity to build up their store of orthographic representations, facilitating a focus on larger units (e.g., "bl-end, blend") and eventually enabling fast access from print to meaning (Share, 1995; Grainger, Lété, Bertand, Dufau, \& Ziegler, 2012). In line with this theory, synthetic phonics encourages children to start with a slow and systematic phonic decoding strategy, which facilitates the development of orthographic representations and ultimately enables children to become independent, fluent readers.

Torgerson et al.'s (2006) meta-analytic review clearly demonstrated that systematic phonics teaching (either analytic or synthetic) is effective for children at risk of reading difficulties, when compared to unsystematic phonics or non-phonics approaches (e.g., whole language). However, there has been very little research comparing the effectiveness of different synthetic phonics programmes (although see Callinan \& van der Zee, 2010, for a small scale comparison of Jolly Phonics and THRASS revealing no clear advantage for either programme). Below, we highlight key differences between the programmes available to schools in England, and motivate our comparison of two of these programmes (Letters and Sounds; DfES, 2007 and the Early Reading Research; Shapiro \& Solity, 2008). Our comparison will focus on the impact of each programme on the reading attainments of children with different levels of phonological awareness (hereafter, PA).

\section{Variation in the Content of Synthetic Phonics Programmes}


There are three key content areas that differ between synthetic phonics programmes. First, the number of letter-sound mappings that are taught. Gontijo et al., (2003) identified 461 possible mappings between letters and sounds in English. Although it is widely held that the optimal number for reading is much less than this, phonics programmes vary in terms of which mappings are taught and the order in which they are introduced (Vousden, Ellefson, Solity \& Chater, 2011). Second, the way high frequency words are taught. Torgerson et al (2006) highlighted that there is insufficient evidence to make clear recommendations about the proportion of a literacy programme that should be devoted to phonics. For example, should children learn high frequency words by sight, or does this undermine their ability to master a phonic decoding strategy? Third, the reading materials that are provided. Should reading materials be explicitly designed to maximize the number of words a child can phonically decode (as in most reading schemes), or should a wide range of texts be available to extend children's choice and the variability of words they encounter (i.e., real books)? The two programmes that are investigated in the current study vary in these three domains (Letters and Sounds, hereafter L\&S and the Early Reading Research, hereafter ERR).

Naturally, both L\&S and ERR programmes include a strong focus on phonic decoding. The key difference is that under L\&S, phonic decoding is the only strategy that is explicitly taught whereas under ERR, children are taught to use two strategies when reading: to recognise the word by sight or to decode it. $L \& S$ can therefore be considered a more intensive synthetic phonics strategy. This difference in focus is reflected in the details of the two programmes. First, ERR teaches only the most frequent pronunciation of each grapheme (see Vousden, 2008). In contrast, L\&S teaches alternative pronunciations (e.g., the grapheme $a$ as in hat, $a$ corn, want; the grapheme $e a$ as in sea, head; see DfES, 2007). Second, ERR teaches 100 highly frequent words by sight (Masterson, Stuart, Dixon \& Lovejoy, 2010; Vousden et al., 2011). This list includes both regular (e.g., up, in, went) and exception words (e.g., you, was, said), but both types of words are taught in the same way under ERR.

Children are taught to recognise each word as a whole and they practice reading sets of these words by sight in every whole class session. Under L\&S, many of the same words are taught as high frequency words but the approach to teaching them is very different. Children are taught to sound out the regular words in full and for the exception words (tricky words), they are taught to recognise parts of each word that are phonically decodable and then sound out as much of the word as possible. Children practice reading these words and are exposed to them in different contexts, with the aim that they will eventually learn to recognise them by 
sight. This difference in approach to high frequency words means that under ERR, children get more practice recognising these words by sight, whereas under $\mathrm{L} \& \mathrm{~S}$, children get more practice in phonically decoding these words. In fact, many words that are initially listed as tricky in the L\&S programme become phonically decodable when alternative mappings are taught. The third key difference between the programmes is the reading materials that are used. Most schools using the L\&S programme combine this with a reading scheme (e.g., the Oxford Reading Tree) which provides books that contain a high proportion of phonically decodable words, appropriate to a child's phonics knowledge. This encourages children to use a phonic decoding strategy when reading independently. In contrast, under ERR, schools are asked to provide a wide range of real books for children to choose from, instead of graded reading schemes. Although teachers direct children towards appropriate books which are shared through paired reading (Topping, 1995), their reading material is not explicitly tailored to their phonics knowledge, and they are encouraged to use two strategies when reading independently: to recognise the word by sight or to decode it.

There are two further important differences between the programmes. One is the way in which phonic decoding is practised. Although both programmes start by teaching oral synthesis and segmentation of words in the absence of print, $\mathrm{L} \& \mathrm{~S}$ quickly moves on to sounding out and blending in the presence of print. Oral synthesis and segmentation is dropped early in the first year of formal schooling. In contrast, ERR includes oral synthesis and segmentation as well as phonic decoding of print in every whole-class lesson throughout the first two years of primary school. Another difference is in the way whole class teaching is structured. ERR is taught in three whole-class sessions of 15 minutes each per day, whereas L\&S is taught in one daily session (usually 1 hour). Therefore, under ERR children receive more frequent practice on their phonic and sight word reading skills, although the total teaching time is usually less.

We expect both programmes to be effective for the group as a whole (since they meet the requirements of a systematic synthetic phonics programme, as defined by Ehri et al., 2001 and Torgerson et al., 2006). Nevertheless, the differences in content are likely to impact on the way children learn to read, and the strategies they use. Most importantly, these differences between programmes are likely to have the greatest impact on children at risk of developing reading difficulties (Rayner, Foorman, Perfetti, Pesetsky \& Seidenberg, 2001). The current study focusses on children beginning school with difficulties in their PA since 
weaknesses in this area are a major cause of reading difficulties (e.g., Melby-Lervåg, Lyster \& Hulme, 2012).

\section{Current Study}

The link between phonological skills and reading is long established (e.g., Wagner \& Torgeson, 1987) and it is widely agreed that PA plays a vital, albeit reciprocal, role in learning to read. Although PA is strongly associated with reading all types of words (MelbyLervåg et al., 2012), recent research has indicated that phonological skills are especially important when reading words that must be phonically decoded (i.e., nonwords; Shapiro, Carroll \& Solity, 2013). Following on from this, we expect that synthetic phonics programmes with an intensive focus on learning a phonic decoding strategy (e.g., L\&S) will draw more heavily on children's PA than programmes that also teach an alternative strategy (e.g., ERR). More specifically, we anticipate a stronger relationship between PA and exception word reading in the $L \& S$ group, since these children were encouraged to phonically decode parts of exception words. We may also observe a stronger relationship between PA and regular word reading for the L\&S group, since they were encouraged to phonically decode all regular words, whereas the ERR group were taught highly frequent regular words by sight. In contrast, we expect that the relationship between PA and nonword reading should be equally strong, since both programmes teach children to phonically decode unfamiliar words.

These differences in teaching methods should have the greatest impact on children with phonological difficulties at school entry, who may find phonic decoding challenging. However, it is not clear how the intensity of phonics teaching would affect these children. Previous research suggests that synthetic phonics instruction is effective at raising the word reading accuracy of children at risk of reading difficulties in the early years (e.g., Torgerson et al., 2006 and see McArthur et al., 2012 for a review of the impact of phonics on poor readers). However, no previous study has compared the effectiveness of different synthetic phonics programmes for these children. It remains possible that teaching a narrower set of phonics skills may be beneficial for motivating poor readers (as suggested by Chen $\&$ Savage, 2014). Also, providing an alternative strategy (recognizing familiar words by sight) may boost their familiarity with our orthography, and provide additional opportunities for reading practice (Stanovich, 1986). The current study uses a quasi-experimental design to compare groups of schools continuing their chosen synthetic phonics programme (L\&S or 
ERR) and addresses two questions. First, whether the relationship between PA and reading is stronger for the L\&S group. Second, whether the programmes differ in their impact on the reading attainments of children who begin school with phonological difficulties.

\section{Method}

\section{Participants}

We approached head teachers who were using a synthetic phonics programme in their school including L\&S and ERR. Seven of these schools delivered L\&S, 10 schools delivered ERR. Three schools delivered another synthetic phonics programme (Read Write Inc; Miskin, 2006), but were excluded from our analyses due to their small sample size. A questionnaire was delivered orally to class teachers at each testing phase to check fidelity to the programme.

A large proportion of pupils attending these schools were eligible for free school meals (L\&S $M=38 \%, S D=20 \%$; ERR $M=35 \%, S D=17 \%$ ). A large proportion of pupils spoke English as an Additional Language (L\&S $M=32 \%, S D=27 \%$; ERR $M=44 \%, S D=$ $29 \%$ ). These measures were included as covariates in the analyses reported below.

We recruited children beginning their Reception year (mean age 4 years, 6 months) in either 2009 (8 schools) or 2010 (9 schools). We collected data from 925 out of 965 children registered in these schools; exclusions were due to lack of consent or at the teacher's request due to severe special educational needs. Some children opted out of certain assessments (see Table 1 for the $n$ for each assessment). We followed up 887 children at the end of Reception (first year of school) and 799 at the end of Year 1 (second year of school). We conducted a further follow up of the 2009 intake at the end of Year 2 (third year of school; 382 children in 7 schools). One school from the 2009 intake dropped out of the study by end Year 2 and other missing data was due to children moving schools.

\section{Assessments}

School entry assessments were conducted in October and November and follow up assessments were conducted in June and July. Tests were conducted one to one by trained research assistants and delivered in a fixed order, over two or three sessions of around 20 minutes. 
At school entry, we measured children's PA using two assessments. The sound completion subtest from the Phonological Abilities Test (PAT; Muter, Hulme \& Snowling, 1997) required children to complete a word by saying either the last syllable or phoneme (e.g., "wa"- ch or, "ca"- $t$ ); scored out of 16. The York Assessment of Reading for Comprehension (YARC; Snowling et al., 2009) included two subtests; a sound isolation subtest in which the child repeated a nonword, then isolated either the first or last phoneme; a sound deletion subtest in which the child to repeated back a real word, then deleted the final syllable or, final, initial or middle phoneme (e.g., "frog" without " $r$ " = "fog"); scored out of 24 for both subtests. Letter sound knowledge was assessed using a YARC subtest including single letters and letter combinations, scored out of 17 . Reading was assessed using the Early Word Recognition test from the YARC, including 15 regular and 15 exception words.

At the end of Reception and end of Year 1, we administered the YARC PA and word recognition tests again, plus the Phonological Assessment Battery nonword reading test (PhAB; Frederickson et al., 1997), scored out of 20.

At the end of Year 2, we repeated the PhAB nonword reading test, plus the British Ability Scales Word Reading Test (BAS II; Elliot et al., 1996), scored out of 90.

Our other measures (vocabulary, rapid naming, digit span, nonword repetition and passage reading) will be examined in a separate paper in which all reading related skills are modelled.

\section{Results}

\section{Exploration of Measures}

Children's performance on all measures is shown in Table 1. Performance on PA at school entry was very poor but a combined measure (average z score) provided an acceptable distribution (skewness and kurtosis < 1) and was well correlated with later reading (Table 2). Many children scored at floor on exception word reading at end Reception and many scored at ceiling on regular word reading at end Year 1 (Table 1). Transforming these scores resulted in an approximately normal distribution (skewness and kurtosis $<1$ ) and these measures were retained.

Children attending the L\&S schools started at a significant advantage on letter sound knowledge $(d=.57)$, but there was no significant difference on PA scores (Table 3$)$. School entry letter knowledge was included as a covariate in all longitudinal analyses. A binary version of the combined PA measure was created (poor PA) to isolate those children with 
poor phonological skills at school entry. Since both our PA tasks required an explicit response, chance levels were close to zero. In order to score above floor, a child must have some awareness of the segmental structure of words, and be able to isolate a word-segment and pronounce this. We defined children with Poor PA as those failing to score above 0 on either PA test (equivalent to an average $\mathrm{z}$ score $<-.9$ ). These children were unable to produce any word segments, despite multiple attempts across three different task-formats (completion, isolation and deletion). These children were spread across schools (L\&S schools: 7\% - 30\%, overall 15\%; ERR schools: $3 \%$ - 40\%, overall 24\%) and our models included school-level variability as a random factor. In order to check whether any effects of poor PA at school entry were similar to effects of other pre-reading skills, we also isolated children with poor letter sound knowledge to provide a comparison measure (14\% of L\&S children and $25 \%$ of ERR children correctly reported the sound of only 3 letters, or fewer). School-entry letter sound knowledge scores were significantly poorer in schools with higher proportions of children eligible for free school meals (FSM; Table 3) and school entry phonological awareness scores were significantly poorer in schools with higher proportions of children with English as an additional language (EAL; Table 3). FSM and EAL were included as covariates in all analyses.

\section{The Effects of Phonological Awareness and Phonics Programme on Reading}

The STATA program, gllamm, (Rabe-Hesketh, Skrondal \& Pickles, 2002) was used to gain maximum likelihood estimates for linear variance-components models. This allowed us to fit two level (child, school) random intercept regression models with covariates. Since multiple schools delivered each phonics programme, it was important to examine whether any effects of phonics programme were robust across school-level as well as child-level variability. We tested a series of models examining the influence of PA and phonics programme at each stage of reading. First, we examined whether the relationship between concurrent PA and reading was different for the two programmes. Second, we examined the effectiveness of each programme on the later reading attainments of children beginning school with poor or good PA. Finally, we examined whether our findings were specific to PA skills, or whether a similar pattern was gained for models that tested the interaction between poor letter sound knowledge at school entry and phonics programme.

\section{Whether the relationship between concurrent $\mathrm{PA}$ and reading varies by phonics} programme. Table 4 shows models examining the predictive power of concurrent PA and 
Phonics programme, plus the interaction between them, on reading attainments at end Reception and Year 1 whilst controlling for FSM and EAL. We found no significant main effects of phonics programme. As expected, we found a main effect of PA on all reading measures, such that children who scored more highly on our PA measure were better readers (Figure 1 illustrates this overall pattern). We found that concurrent PA significantly interacted with phonics programme on exception word reading at both time points. This interaction was also significant on regular words at end Reception. The interaction was nonsignificant on nonwords at both time points and on regular words at Year 1 (although note that many children had reached ceiling on regular words by this time). As shown in Figure 1, there was a closer association between PA and exception word reading for children receiving the L\&S $(r=.70)$ than the ERR programme $(r=.59)$.

The effect of phonics programme on the reading attainments of children starting school with poor phonological awareness. Table 5 shows models examining the predictive power of school-entry Poor PA and Phonics programme, plus the interaction between them, on reading attainments at end Reception, Year 1 and Year 2 whilst controlling for letter sound knowledge at school entry, FSM and EAL. The effects of school entry Poor PA and letter sound knowledge were significant for all models, whereas the impact of Phonics programme was non-significant for all models. The interaction between Poor PA and Phonics programme was significant on all reading measures at end Reception and non-significant on all reading measures at end Year 1 and Year 2 although there was a trend for the same interaction on word reading at Year $2(\mathrm{p}=.065)$. The pattern for each reading measure at the end of Reception is shown in Figure 2, and the trend at Year 2 is shown in Table 6: children with poor PA showed an advantage under ERR whereas children with good PA showed similar performance across the two type of phonics teaching. There was a significant small advantage of the ERR poor PA group on exception word reading at end Reception (Table $7 ; d=.23$ ). The ERR poor PA group's advantage on nonword reading at end Reception was almost significant (Table $7 ; d=.36$ ). Although the advantage on regular word reading was larger in absolute size (Figure 2; $d=.41$ ), this effect was not robust across school-level differences and therefore was not significant in multilevel models (Table 7). Note that we had a small sample of children with poor PA at Year 2 (Table 6). Our sample size for the poor PA group was larger in previous years, when all schools were included in the study (poor PA/whole sample for ERR at end Reception, $n=130 / 566$. ERR at Year 1, $n=121 / 515 . L \& S$ at end Reception, $n=47 / 321 . L \& S$ at Year $1, n=36 / 283$ ). 
The effect of phonics programme on the reading attainments of children starting school with poor letter sound knowledge. Models testing the interaction between poor letter sound knowledge and Phonics programme showed no significant interactions (Table 8). Children starting school with good or poor letter sound knowledge at school entry benefitted to a similar extent from the two types of phonics programmes. Therefore, the interactions described above appear to be specific to PA.

\section{Discussion}

We examined the reading progress of children receiving two of the synthetic phonics programmes available to schools in England (L\&S and ERR). Our sample of 17 schools represents the largest scale comparison of synthetic phonics programmes to date (Callinan \& van der Zee included just 3 schools in their comparison of THRASS and Jolly Phonics) and the only study to compare the effectiveness of different synthetic phonics programmes for children with poor PA. The two programmes we compared differ in three key respects. First, under ERR, children are only taught the most consistent letter-sound mappings whereas L\&S includes alternative pronunciations. Second, under ERR, children are trained to recognize 100 highly frequent words by sight whereas under L\&S, children are initially taught to phonically decode high frequency words as much as possible. Third, the schools using the L\&S programme combined this with a reading scheme whereas schools using ERR provided real books that were not explicitly tailored to their phonics knowledge. Overall, L\&S can be considered the more intensive phonics programme because of the stronger emphasis on a phonic decoding strategy, whereas ERR can be considered a more flexible approach since children are encouraged to use two strategies when reading: either recognise the word by sight, or phonically decode it. We report two novel findings. First, the more intensive synthetic phonics programme (L\&S) heightened the relationship between PA and exception word reading (and also regular word reading in Reception). Second, the effectiveness of the two programmes differed according to children's level of PA at school entry. Whereas children with good PA achieved equally well under either programme, children with poor PA tended to gain higher reading scores under ERR (with a small, significant advantage on exception words at the end of Reception).

\section{The Relationship Between Phonological Awareness and Reading}

We found strong correlations between PA at school entry and later reading attainments, a significant detrimental effect of poor PA at school entry, and a significant 
effect of concurrent PA on reading attainments. Our findings are therefore in line with the enormous body of work suggesting a critical role for PA in reading development (MelbyLervåg et al., 2012). Our novel finding is that this relationship changes depending on the nature of the phonics programme. Specifically, children's concurrent PA was more highly associated with their reading attainments under L\&S. This was significant for exception word reading at the end of the first and second years of school (end Reception and end Year 1). This pattern could be driven by the fact that the exception word test included 5 words taught by sight in the ERR programme (you, was, said, out, what). These were also included as tricky words in the L\&S programme, but children were not given regular practice in recognising them by sight. Alternatively, ERR children may have been generally more flexible in their approach to reading exception words (e.g., more prepared to guess, or to recognise larger units), and therefore relied less on their PA skills. This pattern was also significant on regular word reading at end Reception, possibly because 7 of the regular words in this test were included as sight words in the ERR programme. In contrast, this pattern was non-significant on nonword reading, probably because both L\&S and ERR taught children phonically decode all unfamiliar words.

\section{Effectiveness of the Two Phonics Programmes for Children Starting School with Poor Phonological Awareness}

We found no significant differences in later reading attainments between the two phonics programmes, for the sample as a whole. Thus, there appears to be no clear advantage of an intensive synthetic phonics programme (e.g., in L\&S schools, children were taught alternative pronunciations and provided with phonically decodable texts). Our most consistent finding was that children's phonological skill at school entry interacted with the type of phonics teaching on their reading attainments at the end of Reception (end of the first year of school). There was a trend for children with poor PA to perform better under ERR, whereas the two types of phonics were equivalent for children with good PA. The advantage of ERR for children with poor PA was significant on exception word reading at the end of Reception. One interpretation of this effect is that the ERR schools had a greater proportion of lower achieving pupils and were therefore better equipped to teach them effectively. Nevertheless, there was considerable variability between schools, and our findings were significant over and above these school differences. In fact, we found no equivalent pattern of interactions when children were grouped by their letter sound knowledge, suggesting that this effect was driven by PA specifically rather than generic poor performance. Since this 
interaction was observed over and above school differences, and is specific to phonological skills, we argue that this reflects differences in the teaching programmes.

It is surprising that the interaction was significant for all types of words. In particular, nonwords must be read through a decoding strategy so early PA should be equally important for children receiving either programme. Both programmes focussed on basic mappings during Reception but one difference is that under ERR, children practiced these mappings more regularly (three short sessions per day) and teachers checked children's fluency before moving on to new sounds. This approach may have suited children with poor PA better than the L\&S teaching structure in which these skills were taught in one longer session per day, and the teacher progressed to new sounds each week, rather than checking fluency. Nevertheless, the ERR advantage was only significant for exception word reading at the end of Reception (only approaching significance for regular words). It is possible that children with poor PA were able to benefit from the sight words taught in ERR and recognised more of the exception words in this test than their peers being taught through the L\&S programme. However, given the small size of this effect and the generally low performance of the Poor PA group on this test, we can't make strong claims about the success of ERR pupils' sight word recognition. Nevertheless, this small effect was consistent across schools (i.e., significant in our multi-level models), suggesting that the ERR poor-PA pupils were consistently using a more effective strategy when confronted with these exception words (perhaps they more often attempted sight-recognition, whereas their L\&S peers more often persisted with an unsuccessful phonic decoding strategy).

\section{Implications for Practice}

Two of our findings are especially relevant to practice. First, we found no overall effect of phonics programme. This should be reassuring to practitioners who are confronted with a choice of synthetic phonics programmes: at least for the two programmes we examined, they were equally effective for the majority of children. However, this null effect also suggests that certain aspects of the more intensive L\&S programme may be unnecessary (e.g., teaching alternative pronunciations or providing phonically decodable texts). Second, we found a small advantage of ERR on early exception word reading for children beginning school with poor PA. One interpretation of this second finding is that the children with poor PA were given a boost by learning frequent words by sight. Their poor PA was less likely to 
affect this aspect of learning, and this may have provided encouragement, and allowed them to develop familiarity with the orthography.

\section{Conclusions}

We have highlighted variations in the content of synthetic phonics programmes and shown that different programmes are not equally beneficial for children who begin school with poor PA. The two programmes were equally effective for children with good PA, but children starting school with poor PA showed a small advantage under ERR on exception word reading. ERR teaches only the most consistent letter sound mappings, alongside frequent practice in recognising high frequency words by sight. Although further research is needed to isolate the impact of each aspect of this programme, our findings suggest that including a narrow range of phonic skills is sufficient and explicitly teaching children to use two strategies for reading may benefit children with poor PA. The conclusions from the current study are limited by our use of a quasi-experimental design (our schools were not randomly assigned to phonics programmes). Also, although we had a large sample for the first two years of school, this was reduced at the end of the third year such that we were underpowered to examine the longer term effects of having Poor PA at school entry. Nevertheless, the differences we have highlighted motivates further investigation using experimental studies that systematically vary each element within a single phonics programme. Improving outcomes for children at risk of literacy difficulties has been a key priority of recent UK governments and policymakers have a huge evidence base to draw upon (see Rose, 2009). However, we have made vastly more progress in identifying children at risk than in providing clear guidelines for remediation (e.g., see Rayner, 2001, Vellutino, Fletcher, Snowling \& Scalon, 2004 for similar arguments). The most cost effective way to improve outcomes for these children is to ensure that normal classroom teaching meets their requirements as far as possible. Our findings provide the impetus for a large randomised controlled trial of different phonics programmes, and will ultimately enable clearer guidelines as to the optimal content of these programmes, to increase their effectiveness for all children, particularly those at risk of reading difficulties. 


\section{References}

Callinan, C., \& Zee, E. (2010). A comparative study of two methods of synthetic phonics instruction for learning how to read: Jolly phonics and THRASS. The Psychology of Education Review, 34 (1), 21 - 31.

Chen, V., \& Savage, R. (2014). Evidence for a Simplicity Principle: Teaching Common Complex Grapheme-Phonemes Improves Reading and Motivation in At-Risk Readers. Journal of Research in Reading, 37 (2), 196-214, doi: 10.1111/14679817.12022

Department for Education (DfE) (2013). The National Curriculum in England, available online at https://www.gov.uk/government/collections/national-curriculum

Department for Education and Skills. (2007). Letters and sounds: Principles and practice of high quality phonics. Notes of guidance for practitioners and teachers. Nottingham, UK: DfES Publications. Available online at: https://www.gov.uk/government/publications

Ehri, L. C. (2008). Learning to Read Words: Theory, Findings, and Issues. Scientific Studies of Reading, 9(2), 167-188. doi: 10.1207/s1532799xssr0902_4

Ehri, L.C., Nunes, S.R., Stahl, S.A. and Willows, D.M. (2001) Systematic phonics instruction helps students learn to read: Evidence from the National Reading Panel's metaanalysis Review of Educational Research, 71(3), 393 - 447. doi: 10.3102/00346543071003393

Elliot, C. D., Smith, P., \& McCulloch, K. (1996). British ability scales (2nd ed.). Windsor, UK: NFER.

Frederickson, N., Frith, U. \& Reason, R. (1997). Phonological Assessment Battery (PhAB). Windsor: NFER-Nelson.

Gontijo, P. F. D., Gontijo, I., \& Shillcock, R. (2003). Grapheme-phoneme probabilities in British 
English. Behavior Research Methods, Instruments, and Computers, 35(1), 136-157. doi: 10.3758/bf03195506

Grainger, J., Lété, B., Bertand, D., Dufau, S. \& Ziegler, J.C. (2012). Evidence for multiple routes in learning to read. Cognition, 123 (2), 280-292. doi:

10.1016/j.cognition.2012.01.003

Masterson, J., Stuart, M., Dixon, M., \& Lovejoy, S. (2010). Children's printed word database: Continuities and changes over time in children's early reading vocabulary. British Journal of Educational Psychology, 101 (2), 221-242. doi:

$10.1348 / 000712608 \times 371744$

McArthur, G., Eve, P.M., Jones, K., Banales, E., Kohnen, S., Anandakumar, T. et al. (2012). Phonics training for English-speaking poor readers (Review). Cochrane Database of Systematic Reviews, 12. doi:10.1002/14651858.CD009115.pub2.

Melby-Lervåg, M., Lyster, S., Hulme, C. (2012). Phonological Skills and Their Role in Learning to Read: A Meta-Analytic Review. Psychological Bulletin 138, 322-352. doi: $10.1037 / \mathrm{a} 0026744$

Miskin, R. (2006). Read Write Inc. Phonics Handbook. Oxford University Press. Muter, V., Hulme, C., \& Snowling, M. (1997). The Phonological Abilities Test. The Psychological Corporation, London.

Rabe-Hesketh, S., Skrondal, A., \& Pickles, A. (2002). Reliable estimation of generalized linear mixed models using adaptive quadrature. The Stata Journal, 2(1), 1-21.

Rayner, K., Foorman, B. R., Perfetti, C. A., Pesetsky, D., \& Seidenberg, M. S. (2001). How psychological science informs the teaching of reading. Psychological Science in the Public Interest, 2, 31-74. doi: 10.1111/1529-1006.00004

Rose, J. (2009). Identifying and Teaching Children and Young People with Dyslexia and Literacy Difficulties. Independent report to the Secretary of State for Children, 
Schools and Families, UK, June. Available online at:

http://webarchive.nationalarchives.gov.uk/20130401151715/https://www.education.g ov.uk/publications/

Share, D. L. (1995). Phonological recoding and self-teaching: Sine qua non of reading acquisition. Cognition, 55, 151-218. doi: 10.1016/0010-0277(94)00645-2

Shapiro, L.R. \& Solity, J. (2008). Delivering Phonological and Phonics Training within Whole Class Teaching. The British Journal of Educational Psychology, 78 (4), 597620. doi: $10.1348 / 000709908 \times 293850$

Shapiro, L. R., Carroll, J. M., \& Solity, J. E. (2013). Separating the influences of prereading skills on early word and nonword reading. Journal of Experimental Child Psychology, 116(2), 278295. doi: 10.1016/j.jecp.2013.05.011

Snowling, M.J., Stothard, S.E., Clarke, P., Bowyer-Crane, C., Harrington, A., Nation, K., Truelove, E., \& Hulme, C. (2009).York Assessment of Reading for Comprehension. London: GL Assessment.

Stanovich, K.E. (1986). Matthew effects in reading: Some consequences of individual differences in the acquisition of literacy. Reading Research Quarterly, 21, 360-407. doi: 10.1598/rrq.21.4.1

Topping, K. (1995). Paired Reading, Writing and Spelling. London: Continnuum.

Torgerson, C. J., Brooks, G., \& Hall, J. (2006). A systematic review of the research literature on the use of phonics in the teaching of reading and spelling (DfES Research Rep. 711). Department for Education and Skills, London. Available online at: http://webarchive.nationalarchives.gov.uk/20130401151715/http://www.education.go v.uk/publications

Vellutino, F., Fletcher, J., Snowling, M., \& Scalon, D. (2004). Specific reading disability (dyslexia): what have we learnt in the past four decades. Journal of Child Psychology and Psychiatry, 45, 2 - 40. doi: 10.1046/j.0021-9630.2003.00305.x 
Vousden, J. I. (2008). Units of English spelling-to-sound mapping: A rational approach to reading instruction. Applied Cognitive Psychology, 22 (2), 247 - 272. doi: 10.1002/acp. 1371

Vousden, J.I., Ellefson, M.R., Solity, J., and Chater, N. (2011). Simplifying reading: Applying the simplicity principle to reading. Cognitive Science, 35, 34-78. doi: 10.1111/j.1551-6709.2010.01134.x

Wagner, R. K., \& Torgesen, J. K. (1987). The nature of phonological processing and its causal role in the acquisition of reading skills. Psychological Bulletin, 101, 192-212. doi: 10.1037//0033-2909.101.2.192 


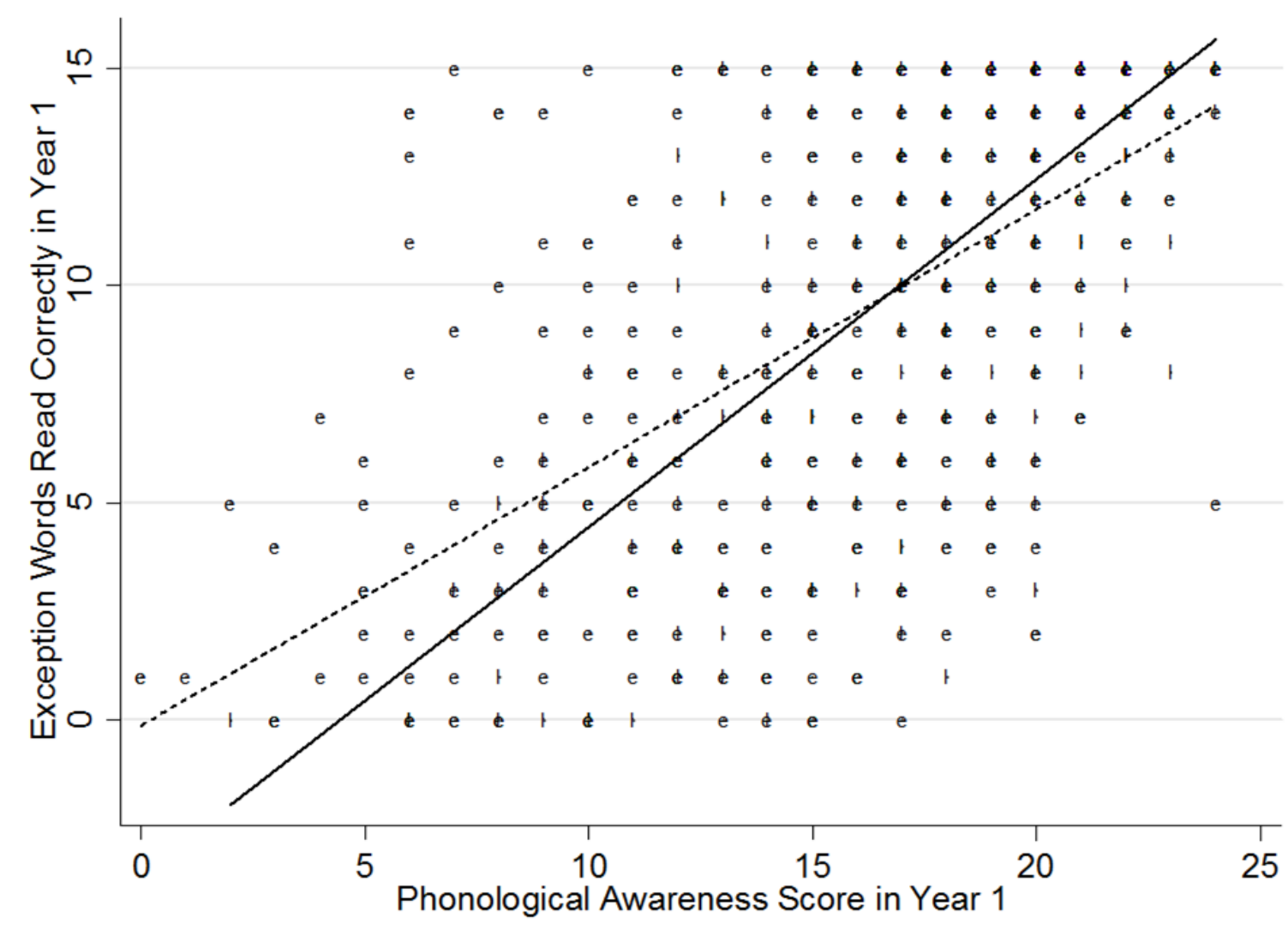

Figure 1. Scatterplot of concurrent phonological awareness and exception word reading scores at Year 1, showing the line of best fit for Letters and Sounds schools (solid line; $r=.70$ ) and Early Reading Research schools (dashed line; $r=.59$ ). Note. Data points from children receiving the Letters and Sounds programme are labelled 1, and data points from children receiving the Early Reading Research programme are labelled e. 


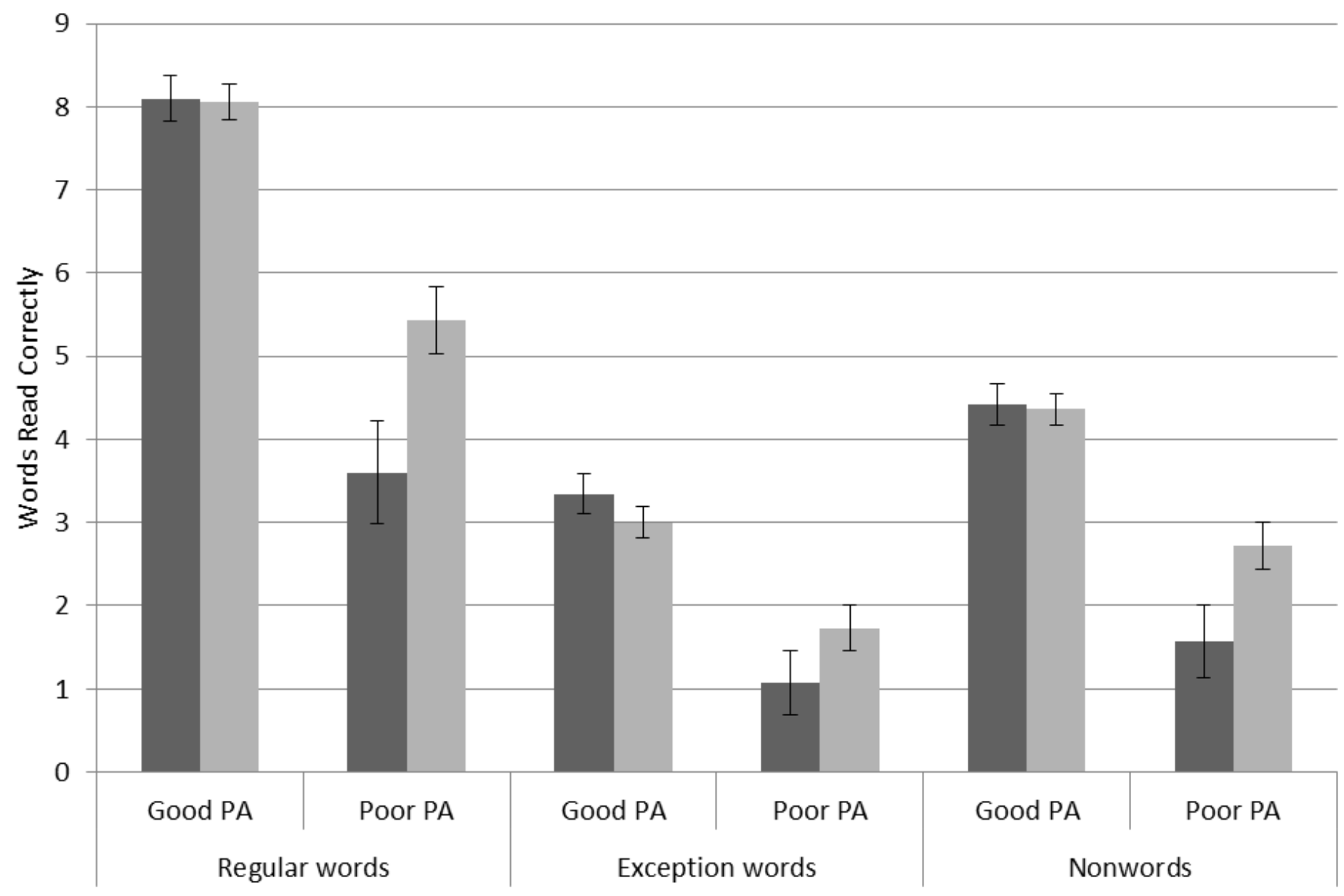

Letters and Sounds

Early Reading Research

Figure 2. Performance on reading measures at end Reception for children with good and poor PA at school entry, attending schools delivering ERR and Letters and Sounds. Note. PA= phonological awareness. The error bars show standard errors collapsed across schools and therefore cannot be used to indicate significant group differences. Our multilevel analyses demonstrate which effects were robust over school-level differences. All interactions between phonics and poor PA were significant (Table 5). The advantage on exception word reading for the poor PA group receiving the Early Reading Research programme was significant and the advantage on nonwords was almost significant (Table 7). 
Table 1

Descriptive Statistics for all Measures Between School Entry and End Year 2, for Children Receiving the Letters and Sounds or Early Reading Research Programme

\begin{tabular}{|c|c|c|c|c|c|c|c|c|c|}
\hline & \multirow[b]{2}{*}{ Measure } & \multicolumn{4}{|c|}{ Letters and Sounds } & \multicolumn{4}{|c|}{ Early Reading Research } \\
\hline & & $M$ & $S D$ & $n$ & $\%$ at floor/ceiling & $M$ & $S D$ & $n$ & $\%$ at floor/ceiling \\
\hline \multirow[t]{3}{*}{ School Entry } & Letter sound knowledge (/17) & 7.91 & 3.63 & 325 & $2 /<1$ & 5.92 & 3.3 & 573 & $3 /<1$ \\
\hline & Sound isolation and deletion (/24) & 5.58 & 5.31 & 321 & $22 / 0$ & 3.57 & 4.19 & 571 & $32 / 0$ \\
\hline & Sound completion $(/ 16)$ & 5.18 & 5.65 & 326 & $42 / 8$ & 4.91 & 5.49 & 577 & $44 / 5$ \\
\hline \multirow[t]{4}{*}{ Year R } & Sound isolation and deletion (/24) & 10.36 & 5.86 & 313 & $4 / 0$ & 9.42 & 5.65 & 557 & $7 /<1$ \\
\hline & Regular word reading $(/ 15)$ & 7.41 & 4.81 & 313 & $9 / 6$ & 7.44 & 4.53 & 556 & $9 / 5$ \\
\hline & Exception word reading (/15) & 3.03 & 3.89 & 313 & $37 / 2^{1}$ & 2.67 & 3.65 & 556 & $35 / 2$ \\
\hline & Nonword reading $(/ 20)$ & 4.02 & 4.11 & 321 & $28 /<1^{\mathrm{s}}$ & 3.93 & 3.85 & 566 & $26 / 0$ \\
\hline \multirow[t]{4}{*}{ Year 1} & Sound isolation and deletion (/24) & 17.84 & 3.87 & 283 & $0 / 2$ & 16.25 & 4.94 & 516 & $<1 / 2$ \\
\hline & Regular word reading $(/ 15)$ & 13.41 & 2.56 & 283 & $<1 / 48^{\mathrm{rl}}$ & 12.56 & 3.32 & 515 & $1 / 40$ \\
\hline & Exception word reading (/15) & 10.72 & 4.41 & 283 & $4 / 28^{\mathrm{s}}$ & 9.54 & 4.90 & 515 & $3 / 22$ \\
\hline & Nonword reading $(/ 20)$ & 11.57 & 4.71 & 263 & $1 / 3$ & 9.89 & 5.23 & 489 & $4 / 3$ \\
\hline \multirow[t]{2}{*}{ Year 2} & Word reading $(/ 90)$ & 52.95 & 15.98 & 118 & $0 / 0$ & 49.81 & 16.07 & 264 & $0 / 0$ \\
\hline & Nonword reading $(/ 20)$ & 13.64 & 4.63 & 118 & $1 / 9$ & 13.09 & 5.01 & 264 & $1 / 8$ \\
\hline
\end{tabular}

Note. Raw scores are shown above. Prior to analysis, the following transformations were used to ensure skewness and kurtosis values were $<1$ : log ${ }^{1}$, square root ${ }^{\mathrm{s}}$, reverse then $\log ^{\mathrm{rl}}$. Sample-specific reliabilities (Chronbach's alpha) ranged from .80 to .96 . 
Table 2

Correlations Between School Entry Letter Sound Knowledge and Phonological Awareness and Later Phonological Awareness and Reading for the Whole Sample

\begin{tabular}{|c|c|c|c|c|c|c|c|c|c|c|c|c|}
\hline & & \multicolumn{2}{|c|}{ School Entry } & \multicolumn{4}{|c|}{ Reception } & \multicolumn{4}{|c|}{ Year 1} & \multirow{2}{*}{$\begin{array}{l}\text { Year } 2 \\
\text { Word }\end{array}$} \\
\hline & & Letter & PA & PA & Regular & Exception & Nonword & PA & Regular & Exception & Nonword & \\
\hline \multirow[t]{2}{*}{ Entry } & Letter & & & & & & & & & & & \\
\hline & PA & .55 & & & & & & & & & & \\
\hline \multirow[t]{4}{*}{ Reception } & PA & .53 & .64 & & & & & & & & & \\
\hline & Regular & .57 & .54 & .69 & & & & & & & & \\
\hline & Exception & .56 & .51 & .66 & .84 & & & & & & & \\
\hline & Nonword & .51 & .49 & .66 & .79 & .71 & & & & & & \\
\hline \multirow[t]{4}{*}{ Year 1} & PA & .42 & .43 & .58 & .47 & .43 & .47 & & & & & \\
\hline & Regular & .46 & .38 & .53 & .55 & .50 & .50 & .64 & & & & \\
\hline & Exception & .52 & .45 & .62 & .64 & .62 & .60 & .63 & .87 & & & \\
\hline & Nonword & .38 & .38 & .51 & .49 & .52 & .51 & .63 & .64 & .70 & & \\
\hline \multirow[t]{2}{*}{ Year 2} & Word & .43 & .43 & .58 & .61 & .61 & .62 & .61 & .69 & .80 & .71 & \\
\hline & Nonword & .32 & .35 & .51 & .54 & .51 & .58 & .60 & .60 & .66 & .69 & .81 \\
\hline
\end{tabular}

Note. All correlations were significant at $p<.001$. Letter $=$ letter sound knowledge, $\mathrm{PA}=$ phonological awareness, Regular $=$ regular word reading, Exception $=$ exception word reading, Nonword $=$ nonword reading, Word $=$ word reading. 
Table 3

Regression Models Examining differences between Phonics Programmes and Multi-level Random Effects on School Entry Skills

\begin{tabular}{|c|c|c|c|c|}
\hline \multirow[b]{2}{*}{ Fixed effects } & \multicolumn{2}{|c|}{ Letter Sound Knowledge } & \multicolumn{2}{|c|}{ Phonological Awareness } \\
\hline & Coef. & $S E$ & Coef. & $S E$ \\
\hline Phonics Programme & $-1.68 *$ & .69 & -1.02 & .58 \\
\hline FSM & $-0.04 *$ & .02 & $-0.07 *$ & .01 \\
\hline EAL & -0.02 & .01 & $-0.02 *$ & .01 \\
\hline Random effects & Var. & $S E$ & Var. & $S E$ \\
\hline Child & 9.75 & .46 & 18.45 & .88 \\
\hline School & 1.60 & .64 & 0.87 & .43 \\
\hline Log likelihood & -2315.44 & & -2607.81 & \\
\hline
\end{tabular}

Note. $* p<.05$. Coef. $=$ coefficient, Var $=$ variance. $\mathrm{FSM}=$ Free School Meals eligibility (coded 0 or 1$)$. EAL = English as an Additional Language (coded 0 or 1$).$ The Letters and Sounds Phonics programme was coded 0, the Early Reading Research Phonics programme was coded 1, therefore the negative co-efficients of Phonics Programme indicate a disadvantage for the Early Reading Research programme over the Letters and Sounds programme. 
Table 4

Regression Models Examining Effects of Phonics Programme, Phonological Awareness, the Interaction Between Phonics Programme and Phonological Awareness and Multi-level Random Effects on Concurrent Reading Outcomes

\begin{tabular}{|c|c|c|c|c|c|c|c|c|c|c|c|c|}
\hline \multirow[b]{3}{*}{ Fixed effects } & \multicolumn{6}{|l|}{ Reception } & \multicolumn{6}{|l|}{ Year 1} \\
\hline & \multicolumn{2}{|l|}{ Regular } & \multicolumn{2}{|c|}{ Exception } & \multicolumn{2}{|l|}{ Nonword } & \multicolumn{2}{|l|}{ Regular } & \multicolumn{2}{|c|}{ Exception } & \multicolumn{2}{|l|}{ Nonword } \\
\hline & Coef. & $S E$ & Coef. & $S E$ & Coef. & $S E$ & Coef. & $S E$ & Coef. & $S E$ & Coef. & $S E$ \\
\hline \multicolumn{13}{|l|}{ Phonics } \\
\hline Programme & 0.70 & .70 & 0.14 & .12 & -0.07 & .13 & -0.07 & .82 & 0.34 & .23 & 1.31 & 1.48 \\
\hline PA & $0.58 * * *$ & .03 & $0.11 * * *$ & .01 & $0.09 * * *$ & .01 & $0.44 * * *$ & .04 & $0.14 * * *$ & .01 & $0.81 * * *$ & .07 \\
\hline FSM & -0.03 & .02 & -0.003 & .003 & -0.005 & .003 & $-0.03 *$ & .01 & $-0.01 *$ & .003 & -0.01 & .02 \\
\hline EAL & 0.02 & .01 & 0.002 & .002 & 0.002 & .002 & -0.01 & .01 & -0.001 & .002 & 0.002 & .01 \\
\hline Phonics x PA & $-0.08 *$ & .04 & $-0.02 *$ & .01 & 0.001 & .01 & -0.01 & .04 & $-0.02 *$ & .01 & -0.11 & .08 \\
\hline \multicolumn{13}{|l|}{ Random } \\
\hline effects & Var. & $S E$ & Var. & $S E$ & Var. & $S E$ & Var. & $S E$ & Var. & $S E$ & Var. & $S E$ \\
\hline Child & 9.11 & .44 & 0.39 & .02 & 0.37 & .02 & 5.06 & .26 & 0.37 & .02 & 14.53 & .76 \\
\hline School & 1.11 & .44 & 0.02 & .01 & 0.03 & .01 & 0.43 & .19 & 0.05 & .02 & 0.97 & .44 \\
\hline Log likelihood & -2209.20 & & -836.98 & & -810.16 & & -1792.21 & & -750.18 & & -2084.21 & \\
\hline
\end{tabular}

Note. $* p<.05, * * p<.01, * * * p<.001$. Coef. $=$ coefficient, Var. $=$ variance. Regular $=$ regular word reading, Exception $=$ exception word reading, Nonword $=$ nonword reading, $\mathrm{PA}=$ phonological awareness (continuous measure). FSM = Free School Meals eligibility (coded 0 or 1). EAL = English as an Additional Language (coded 0 or 1 ). The Letters and Sounds Phonics programme was coded 0, the Early Reading Research Phonics programme was coded 1. See Figure 1 for an illustration of the Phonics x PA interaction pattern. 
Table 5

Regression Models Examining Effects of Phonics Programme, Poor Phonological Awareness, Letter Sound Knowledge, the Interaction Between Phonics Programme and Poor Phonological Awareness and Multi-level Random Effects on Later Reading Outcomes

\begin{tabular}{|c|c|c|c|c|c|c|c|c|c|c|c|c|}
\hline \multirow[b]{3}{*}{ Fixed effects } & \multicolumn{6}{|l|}{ Reception } & \multicolumn{6}{|l|}{ Year 1} \\
\hline & \multicolumn{2}{|l|}{ Regular } & \multicolumn{2}{|l|}{ Exception } & \multicolumn{2}{|l|}{ Nonword } & \multicolumn{2}{|l|}{ Regular } & \multicolumn{2}{|l|}{ Exception } & \multicolumn{2}{|l|}{ Nonword } \\
\hline & Coef. & $S E$ & Coef. & $S E$ & Coef. & $S E$ & Coef. & $S E$ & Coef. & $S E$ & Coef. & $S E$ \\
\hline Phonics Programme & 0.43 & .69 & 0.07 & .12 & 0.03 & .14 & -0.15 & .55 & -0.04 & .14 & -0.78 & 1.10 \\
\hline Poor PA & $-2.01 * * *$ & .54 & $-0.27 *$ & .11 & $-0.30 * *$ & .11 & $-1.64 * * *$ & .47 & $-0.47 * * *$ & .12 & $-2.31 *$ & .91 \\
\hline Letter & $0.78 * * *$ & .04 & $0.15^{* *}$ & .01 & $0.13 * * *$ & .01 & $0.40 * * *$ & .03 & $0.13 * * *$ & .01 & $0.65 * * *$ & .06 \\
\hline FSM & $-0.04 \uparrow$ & .02 & -0.01 & .004 & $-0.01 *$ & .004 & -0.01 & .02 & -0.004 & .004 & 0.01 & .03 \\
\hline EAL & 0.02 & .01 & 0.003 & .002 & 0.003 & .003 & 0.001 & .01 & 0.002 & .003 & 0.01 & .02 \\
\hline Phonics x Poor PA & $1.35^{*}$ & .64 & $0.27 *$ & .13 & $0.28 *$ & .13 & 0.63 & .55 & 0.23 & .14 & 1.58 & 1.05 \\
\hline Random effects & Coef. & $S E$ & Coef. & $S E$ & Coef. & $S E$ & Coef. & $S E$ & Coef. & $S E$ & Coef. & $S E$ \\
\hline Child & 10.49 & .52 & 0.44 & .02 & 0.43 & .02 & 6.51 & .34 & 0.45 & .02 & 19.26 & 1.03 \\
\hline School & 1.52 & .59 & 0.05 & .02 & 0.07 & .03 & 0.93 & .41 & 0.06 & .03 & 3.98 & 1.65 \\
\hline Log likelihood & -2198.86 & & -859.82 & & -869.37 & & -1827.59 & & -797.81 & & -2119.7 & \\
\hline
\end{tabular}

Note. $\dagger p=.05, * p<.05, * * p<.01, * * * p<.001$. Coef. $=$ coefficient, Var. = variance. Regular $=$ regular word reading, Exception $=$ exception word reading, Nonword= nonword reading, Letter $=$ letter sound knowledge, Poor PA= phonological awareness group $(0=$ Good PA, $1=$ Poor PA). FSM = Free School Meals eligibility $($ coded 0 or 1). EAL = English as an Additional Language (coded 0 or 1). The Letters and Sounds Phonics programme was coded 0, the Early Reading Research Phonics programme was coded 1. See Figure 2 for an illustration of the Phonics x Poor PA interaction pattern). 
Table 5, cont.

Regression Models Examining Effects of Phonics Programme, Poor Phonological Awareness, Letter Sound Knowledge, the Interaction Between Phonics Programme and Poor Phonological Awareness and Multi-level Random Effects on Later Reading Outcomes

\begin{tabular}{|c|c|c|c|c|}
\hline & Year 2 & & & \\
\hline & Word reading & & Nonword reading & \\
\hline Fixed effects & Coef. & $S E$ & Coef. & $S E$ \\
\hline Phonics Programme & 2.81 & 1.99 & -0.15 & .80 \\
\hline Poor PA & $-14.48 * * *$ & 4.29 & $-4.35 * *$ & 1.38 \\
\hline Letter & $2.36 * * *$ & .24 & $0.60 * * *$ & .08 \\
\hline FSM & -0.44 & .09 & $-0.09 * *$ & .03 \\
\hline EAL & 0.14 & .04 & $0.07 * * *$ & .01 \\
\hline Phonics x Poor PA & 8.77 & 4.75 & 1.94 & 1.54 \\
\hline Random effects & Coef. & $S E$ & Coef. & $S E$ \\
\hline Child & 177.55 & 13.14 & 18.48 & 1.38 \\
\hline School & 0.00 & .00 & 0.16 & .33 \\
\hline Log likelihood & -1463.12 & & -1051.40 & \\
\hline
\end{tabular}

Note. $* * p<.01, * * * p<.001$. Coef. $=$ coefficient, Var. $=$ variance, Letter $=$ letter sound knowledge, Poor PA= phonological awareness group $(0=$ Good PA, $1=$ Poor PA $)$. FSM $=$ Free School Meals eligibility (coded 0 or 1). EAL = English as an Additional Language (coded 0 or 1). The Letters and Sounds Phonics programme was coded 0, the Early Reading Research Phonics programme was coded 1. 
Table 6

Descriptive Statistics for Word Reading at the End of Year 2, for Children who Started School with Good or Poor Phonological Awareness Receiving Either the Letters and Sounds or Early Reading Research Programme

\begin{tabular}{lllllllll}
\hline & \multicolumn{3}{l}{ Letters and Sounds } & \multicolumn{4}{c}{ Early Reading Research } \\
\hline & $M$ & $S D$ & $n$ & range & $M$ & $S D$ & $n$ & range \\
\hline Poor Phonological Awareness group & 33.18 & 20.28 & 11 & $5-68$ & 43.2 & 15.42 & 60 & $7-69$ \\
Good Phonological Awareness group & 55.02 & 14.25 & 104 & $10-78$ & 52.23 & 15.53 & 196 & $12-80$ \\
\hline
\end{tabular}


Table 7

Regression Models Examining Effects of Phonics Programme, Letter Sound Knowledge and Multi-level Random Effects on Later Reading Outcomes, for Children with Poor or Good Phonological Awareness at School Entry

\begin{tabular}{|c|c|c|c|c|c|c|}
\hline Poor PA group & Reception & & & & & \\
\hline & Regular word reading & & Exception word reading & & Nonword reading & \\
\hline Fixed effects & Coef. & $\mathrm{SE}$ & Coef. & SE & Coef. & SE \\
\hline Phonics Programme & 1.77 & 1.11 & $0.36^{\times}$ & .15 & $0.35^{\sim}$ & .17 \\
\hline Letter & $0.71 * * *$ & .10 & $0.12 * * *$ & .02 & $0.09 * * *$ & .02 \\
\hline FSM & -0.05 & .04 & -0.01 & .005 & $-0.01^{\times}$ & .01 \\
\hline EAL & 0.01 & .02 & 0.001 & .003 & 0.000 & .003 \\
\hline Random effects & Var. & SE & Var. & SE & Var. & SE \\
\hline Child & 11.06 & .10 & 0.41 & .05 & 0.43 & .05 \\
\hline School & 2.93 & 1.50 & 0.03 & .02 & 0.05 & .03 \\
\hline log likelihood & -479.03 & & -178.12 & & -186.84 & \\
\hline \multirow[t]{2}{*}{ Good PA group } & \multicolumn{6}{|l|}{ Reception } \\
\hline & \multicolumn{2}{|l|}{ Regular word reading } & \multicolumn{2}{|l|}{ Exception word reading } & \multicolumn{2}{|l|}{ Nonword reading } \\
\hline Fixed effects & Coef. & $\mathrm{SE}$ & Coef. & SE & Coef. & $\mathrm{SE}$ \\
\hline Phonics Programme & 0.31 & .71 & 0.04 & .13 & 0.0004 & .15 \\
\hline Letter & $0.79 * * *$ & .04 & $0.16^{* * *}$ & .01 & $0.14 * * *$ & .01 \\
\hline FSM & -0.04 & .02 & -0.01 & .004 & -0.01 & .005 \\
\hline EAL & 0.02 & .01 & 0.003 & .003 & 0.004 & .003 \\
\hline Random effects & Var. & $\mathrm{SE}$ & Var. & $\mathrm{SE}$ & Var. & $\mathrm{SE}$ \\
\hline Child & 9.98 & .55 & 0.44 & .02 & 0.42 & .02 \\
\hline School & 1.61 & .65 & 0.06 & .02 & 0.07 & .03 \\
\hline Log likelihood & -1734.96 & & -686.88 & & -686.18 & \\
\hline
\end{tabular}


Note. $\sim p=.04$ (almost significant, following bonferroni correction) ${ }^{\times} p<.025$ (significant following bonferroni correction), $* * p<.01, * * * p<.001$. Coef. $=$ coefficient, Var. $=$ variance, Letter $=$ letter sound knowledge, Poor PA= phonological awareness group $(0=$ Good PA, $1=$ Poor PA). FSM = Free School Meals eligibility $($ coded 0 or 1$)$. EAL $=$ English as an Additional Language (coded 0 or 1). The Letters and Sounds Phonics programme was coded 0, the Early Reading Research Phonics programme was coded 1. We only explored group differences when a significant interaction was found (Table 5). See Figure 2 for an illustration of the effect of Phonics on each group. 
Table 8

Regression Models Examining Effects of Phonics Programme, Poor Letter Sound Knowledge, the Interaction Between Phonics Programme and Poor Letter Sound Knowledge and Multi-level Random Effects on Later Reading Outcomes

\begin{tabular}{|c|c|c|c|c|c|c|c|c|c|c|c|c|}
\hline \multirow[b]{3}{*}{ Fixed effects } & \multicolumn{6}{|c|}{ Reception } & \multicolumn{6}{|l|}{ Year 1} \\
\hline & \multicolumn{2}{|l|}{ Regular } & \multicolumn{2}{|l|}{ Exception } & \multicolumn{2}{|l|}{ Nonword } & \multicolumn{2}{|l|}{ Regular } & \multicolumn{2}{|l|}{ Exception } & \multicolumn{2}{|l|}{ Nonword } \\
\hline & Coef. & $S E$ & Coef. & $S E$ & Coef. & $S E$ & Coef. & $S E$ & Coef. & $S E$ & Coef. & $S E$ \\
\hline Phonics Programme & -0.27 & .72 & -0.09 & .12 & -0.09 & .14 & -0.60 & .49 & -0.19 & .12 & -1.16 & .85 \\
\hline Poor Letter & $-4.17 * * *$ & .67 & $-0.73 * * *$ & .13 & $-0.66 * * *$ & .14 & $-3.21 * * *$ & .50 & $-0.96 * * *$ & .14 & $-2.15^{*}$ & .96 \\
\hline FSM & $-0.07 * *$ & .02 & $-0.01 * *$ & .004 & $-0.01 * *$ & .004 & $-0.03 *$ & .01 & $-0.01 *$ & .004 & -0.004 & .03 \\
\hline EAL & 0.01 & .01 & 0.001 & .002 & 0.001 & .003 & -0.004 & .01 & 0.000 & .002 & -0.002 & .02 \\
\hline Phonics x Poor Letter & 0.26 & .78 & 0.15 & .16 & 0.09 & .15 & 0.43 & .58 & 0.19 & .16 & -1.42 & 1.10 \\
\hline Random effects & Var. & $S E$ & Var. & $S E$ & Var. & $S E$ & Var. & $S E$ & Var. & $S E$ & Var. & $S E$ \\
\hline Child & 14.85 & .73 & 0.61 & .03 & 0.56 & .03 & 7.40 & .38 & 0.55 & .03 & 22.59 & 1.20 \\
\hline school & 1.56 &. .64 & 0.04 & .02 & 0.06 & .02 & 0.55 & .27 & 0.04 & .02 & .2 .00 & .98 \\
\hline Log likelihood & -2362.01 & & -1006.25 & & -989.30 & & -1887.40 & & -877.65 & & -2189.25 & \\
\hline
\end{tabular}

Note. $* p<.05, * * * p<.001$. Coef. $=$ coefficient, Var. $=$ variance, Poor Letter= letter sound knowledge group $(0=$ Good Letter, $1=$ Poor Letter $)$ FSM $=$ Free School Meals eligibility (coded 0 or 1). EAL = English as an Additional Language (coded 0 or 1 ). The Letters and Sounds Phonics programme was coded 0, the Early Reading Research Phonics programme was coded 1. 
Table 8 cont.

Regression Models Examining Effects of Phonics Programme, Poor Letter Sound Knowledge, the Interaction Between Phonics Programme and Poor Letter Sound Knowledge and Multi-level Random Effects on Later Reading Outcomes

\begin{tabular}{|c|c|c|c|c|}
\hline & Year 2 & & & \\
\hline & Word reading & & Nonword reading & \\
\hline Fixed effects & Coef. & $S E$ & Coef. & $S E$ \\
\hline Phonics Programme & -2.32 & 2.08 & -1.28 & .65 \\
\hline Poor Letter & -13.22 & 7.76 & $-4.72 \dagger$ & 2.41 \\
\hline FSM & $-0.44 * * *$ & .10 & $-0.08 * *$ & .03 \\
\hline EAL & 0.05 & .04 & 0.04 & .01 \\
\hline Phonics*Poor Letter & 2.73 & 8.07 & 1.62 & 2.50 \\
\hline Random effects & Var. & $S E$ & Var. & $S E$ \\
\hline Child & 230.71 & 16.94 & 22.13 & 1.64 \\
\hline School & 0.000 & .000 & 0.07 & .24 \\
\hline Log likelihood & -1535.76 & & -1101.48 & \\
\hline
\end{tabular}

Note. $\dagger p=.05, * * p<.01, * * * p<.001$, Coef. $=$ coefficient, Var. $=$ variance, Poor Letter= letter sound knowledge group $(0=$ Good Letter, $1=$ Poor Letter $)$. FSM $=$ Free School Meals eligibility (coded 0 or 1 ). EAL = English as an Additional Language (coded 0 or 1 ). The Letters and Sounds Phonics programme was coded 0, the Early Reading Research Phonics programme was coded 1. 